\title{
EMERGÊNCIA DE PLÂNTULAS DE FAVEIRA (Clitoria fairchildiana R.A. Howard) EM DIFERENTES SUBSTRATOS
}

\author{
Breno Marques da Silva e Silva* \\ Ivanize Maria Barros dos Santos** \\ Paulo Adller Alves de Araújo*** \\ Rubiene Neto Soares ${ }^{* * * *}$ \\ Camila de Oliveira e Silva ${ }^{* * * * *}$
}

RESUMO: Clitoria fairchildiana R.A. Howard, vulgarmente conhecida como faveira, é uma espécie arbórea utilizada na arborização e recomendada para recuperação de áreas degradadas. O objetivo da presente pesquisa foi a avaliação do uso da casca de eucalipto na composição do substrato para a emergência de plântulas de faveira. Na avaliação dos substratos, as sementes foram colocadas em caixas de plástico entre areia, solo, casca de eucalipto, areia e casca de eucalipto $(3: 1 ; 1: 1 ; 1: 3)$, solo e casca de eucalipto $(3: 1$; $1: 1 ; 1: 3)$ e areia, casca de eucalipto e solo $(1: 1: 1 ; 1: 2: 1 ; 1: 4: 1)$, mantidas em casa de vegetação. Foram avaliados a porcentagem, velocidade de emergência e a biometria das plântulas de faveira. A emergência de plântulas de faveira é menos influenciada pelas proporções de eucalipto no substrato (solo e/ou areia) em comparação com o vigor de suas plântulas. Os substratos mais adequados para a emergência de plântulas de faveira são areia (A), casca de eucalipto triturada (C), Solo (S) + C (3:1), S + C (1:3), A + C (3:1) e A + C (1:3).

PALAVRAS-CHAVE: Fabaceae; Germinação de sementes; Produção de mudas.

\section{EMERGENCE OF CLITORIA FAIRCHILDIANA R.A. HOWARD SEEDLINGS AT DIFFERENT SUBSTRATES}

\begin{abstract}
Clitoria fairchildiana R.A. Howard, commonly known as faveira, is an arboreal species used for reforestation and recommended for the recovery of degraded areas. The bark of the eucalyptus tree in the composition of the substrate for the emergence of faveira seedlings is assessed. Seeds were placed in plastic boxes with sand, soil, eucalyptus bark, sand and eucalyptus bark $(3: 1 ; 1: 1 ; 1: 3)$, soil and eucalyptus bark $(3: 1 ; 1: 1 ; 1: 3)$ and sand, eucalyptus bark and soil $(1: 1: 1 ; 1: 2: 1 ; 1: 4: 1)$ and maintained in a greenhouse. Percentage, emergence speed and biometry of the

\footnotetext{
Doutor em Agronomia (Produção e Tecnologia de sementes); Docente Dr. do Colegiado de Engenharia Florestal da Universidade do Estado do Amapá (UEAP), Macapá (AP), Brasil. E-mail: breno.silva@ueap.edu.br.

** Bacharel em Ciências Ambientais. Universidade Federal do Amapá (UNIFAP), Macapá (AP), Brasil.

${ }^{* * *}$ Graduando em Engenharia Florestal. Universidade do Estado do Amapá (UEAP), Macapá (AP), Brasil.

**** Graduando em Engenharia Florestal. Universidade do Estado do Amapá (UEAP), Macapá (AP), Brasil.

${ }^{* * * * *}$ Especialista em Economia Verde. Prof. Espa. da Prefeitura Municipal do Porto Grande (AP), Brasi
} 
faveira seedlings were evaluated. The emergence of faveira seedlings is less affected by the eucalyptus proportion in the substrate (soil and/or sand) when compared to the seedlings' strength. The most adequate substrates for the emergence of faveira seedlings are sand (A), ground eucalyptus bark (C), Soil (S) and (S) + C (3:1), S + $\mathrm{C}(1: 3), \mathrm{A}+\mathrm{C}(3: 1)$ and $\mathrm{A}+\mathrm{C}(1: 3)$.

KEY WORDS: Fabaceae; Germination of seeds; Production of seedlings.

\section{INTRODUÇÃO}

Dentre as espécies arbóreas nativas da Amazônia, Clitoria fairchildinana R.A. Howard, conhecida como faveira, sombreiro ou palheteira, é utilizada principalmente na arborização urbana, recuperação de áreas degradadas (SOUZA et al., 2007; BLUM et al., 2008; LORENZI, 2008) e uso medicinal e farmacêutico, pois apresentam atividades antinociceptivas, anti-inflamátorias e antioxidantes (LEITE et al., 2012; ANNEGOWDA et al., 2013).

As sementes de faveira são exalbuminosas, orbiculares e achatadas, castanho-esverdeadas, glabra e levemente rugosas, medindo cerca de $13,4 \mathrm{~mm}$ de comprimento, 14,2 $\mathrm{mm}$ de largura e $3 \mathrm{~mm}$ de espessura e com germinação fanerocotiladonar epígea (SILVA; MÔRO, 2008). De acordo com Silva e Carvalho (2008), a germinação de faveira não é afetada pelo tamanho da semente, mas sim, o vigor, pois as sementes grandes e médias originam plântulas mais vigorosas, sendo que o excesso de água reduz a germinação e, a falta, o crescimento das plântulas de faveira.

A renovação da vegetação, recuperação de áreas degradadas, estabelecimento de bancos de germoplasma, programas de melhoramento e plantio para exploração econômica de frutos, madeiras e produtos medicinais são baseados na coleta de sementes e propagação dessas espécies, sendo fundamentais os conhecimentos sobre a dormência e a germinação das sementes, assim como a propagação vegetativa das espécies nativas (SANO et al., 2008).

O conhecimento sobre a germinação é muito importante, visando o manejo adequado para obtenção de mudas de qualidade com baixos custos, pois há possibilidade de controle e modificação de fatores ambientais para o aumento da 
germinação e emergência, diminuindo os gastos e obtendo-se assim mudas de qualidade para os mais diversos fins (NASSIF et al., 1998).

O substrato básico para a produção de mudas é do tipo orgânico como os compostos de esterco de curral curtido, pó da casca de coco seco, cascas de eucaliptos e pinus, bagacilho de cana, húmus de minhoca, entre outros. Esses substratos são, geralmente, utilizados em misturas com outros substratos de menor densidade como a casca de arroz carbonizada e a vermiculita. A adição desses substratos reduz a densidade média da mistura, melhorando suas condições de aeração e drenagem (MARKUS; BANKS, 1999; GONÇALVES et al., 2000; FLORIANDO, 2004; SANTOS et al., 2008).

Para eucalipto (Eucalyptus urophylla S.T. Blake) e faveira, os substratos compostos por casca de eucalipto são adequados para a germinação e/ou crescimento das mudas (FREITAS et al., 2010; SILVA; CESARINO, 2014).

A serragem de madeira tem sido utilizada para a germinação de sementes e produção de mudas de bromélia cravo (Tillandsia geminiflora Brongn), buva (Conyza bonariensis (L.) Cronquist), caruru (Amaranthus retroflexus L.), tamareira (Phoenix roebelenii O 'Brien) faveira (IOSSI et al., 2003; STRINGHETA et al., 2005; LIMA et al., 2008; YAMASHITA et al., 2012; SILVA; CESARINO, 2014). Dessa forma, para o auxílio na produção de mudas em viveiro, o objetivo no presente trabalho foi avaliar o uso da casca de eucalipto na composição do substrato para a emergência de plântulas de faveira.

\section{MATERIAL E MÉTODOS}

Os frutos maduros de faveira foram colhidos de 20 árvores matrizes localizadas na Praça Beira Rio, Praça do Barão do Rio Branco, Praça da Bandeira, Praça Veiga Cabral e Praça Floriano Peixoto, em Macapá (AP), Brasil. Posteriormente, o beneficiamento e a análise das sementes de faveira foram realizados no Viveiro de Mudas e Laboratório de Sementes Florestais da Universidade do Estado do Amapá, em Macapá (AP), Brasil.

As cascas das árvores de eucalipto (Eucaliptus urograndis) foram doadas pela Empresa Amapá Celulose S/A, localizada na cidade de Santana (AP), Brasil. 
O teor de água das sementes foi determinado por meio da secagem de 2 repetições de $10 \mathrm{~g}$ de sementes em estufa a $105^{\circ} \mathrm{C} \pm 3$, durante 24 horas, conforme o recomendado pela Regras para Análise de Sementes (BRASIL, 2009).

Para a avaliação da emergência de plântulas, cinco repetições de 25 sementes foram colocadas a $1 \mathrm{~cm}$ de profundidade (SILVA; CESARINO, 2014) nos substratos (Tabela 1), em bandejas de plástico $(6 \times 20 \times 30 \mathrm{~cm})$, mantidas em casa de vegetação a $50 \%$ de sombreamento (PORTELA et al., 2001). Em seguida, diariamente, a umidade dos substratos foi mantida com 40 a $60 \%$ da capacidade de retenção de água, de acordo com Silva e Carvalho (2008).

Tabela 1. Composição dos substratos para a emergência de plântulas de faveira

\begin{tabular}{cccc}
\hline Composição & Areia (v/v) & Solo (v/v) & Casca de eucalipto (v/v) \\
\hline Substrato (S) 1 & 1 & 0 & 0 \\
S2 & 1 & 0 & 0 \\
S3 & 1 & 0 & 0 \\
S4 & 0 & 1 & 1 \\
S5 & 0 & 3 & 1 \\
S6 & 0 & 1 & 3 \\
S7 & 1 & 0 & 1 \\
S8 & 1 & 0 & 3 \\
S9 & 3 & 0 & 1 \\
S10 & 1 & 1 & 2 \\
S11 & 1 & 1 & 4 \\
S12 & 1 & 1 & \\
\hline
\end{tabular}

Fonte: Dados da pesquisa

O número de plântulas normais foi determinado diariamente, segundo descrição de Silva e Môro (2008) e Brasil (2009). Em seguida, a porcentagem e o índice de velocidade de emergência foram calculados (HONG et al., 2005; CARVALHO; NAKAGAWA, 2012).

O número de folhas, o comprimento do epicótilo, hipocótilo, raiz, parte 
aérea e total, além da razão parte aérea/raiz das plântulas foram determinados por meio da mensuração com régua de todas as plântulas emergidas aos 30 dias após a semeadura (BENINCASA, 2003).

O delineamento experimental foi inteiramente casualizado. Para a análise de variância, foi aplicado o Teste $\mathrm{F}$ e, quando significativo, as comparações entre as médias foram realizadas por meio do Teste de Tukey ao nível de 5\% de probabilidade (ZAR, 1999).

\section{RESULTADOS E DISCUSSÃO}

A porcentagem de emergência de plântulas de faveira foi semelhante para todos os tratamentos avaliados (Tabela 2). Silva e Cesarino (2014) observaram porcentagens de germinação de faveira semelhante em papel, areia, vermiculita e Plantmax ${ }^{\circledR}$, corroborando os resultados observados e indicando a não influência do substrato na porcentagem de germinação.

Tabela 2. Porcentagem de emergência e índice de velocidade de emergência (IVE) de plântulas de faveira (Clitoria fairchildiana R.A. Howard. - Fabaceae) em substratos compostos por diferentes proporções de solo, areia e casca de eucalipto

(continua)

\begin{tabular}{ccc}
\hline Substratos & Emergência (\%) & Velocidade de emergência (Dias $\left.{ }^{-1}\right)$ \\
\hline Areia (A) & $91,0 \mathrm{a}$ & $2,540 \mathrm{a}$ \\
Solo (S) & $77,0 \mathrm{a}$ & $1,792 \mathrm{~b}$ \\
Casca de Eucalipto (C) & $91,0 \mathrm{a}$ & $2,691 \mathrm{a}$ \\
S + C (1:1) & $78,0 \mathrm{a}$ & $2,073 \mathrm{~b}$ \\
$(3: 1)$ & $90,0 \mathrm{a}$ & $2,582 \mathrm{a}$ \\
$(1: 3)$ & $84,0 \mathrm{a}$ & $2,393 \mathrm{a}$ \\
A + C (1:1) & $83,0 \mathrm{a}$ & $2,228 \mathrm{~b}$ \\
$(1: 3)$ & $91,0 \mathrm{a}$ & $2,493 \mathrm{a}$ \\
$(3: 1)$ & $84,0 \mathrm{a}$ & $2,401 \mathrm{a}$
\end{tabular}


(conclusão)

\begin{tabular}{ccc}
\hline Substratos & Emergência (\%) & Velocidade de emergência $\left(\right.$ Dias $\left.^{-1}\right)$ \\
\hline $\mathrm{A}+\mathrm{C}+\mathrm{S}(1: 1: 1)$ & $82,0 \mathrm{a}$ & $1,946 \mathrm{~b}$ \\
$(1: 2: 1)$ & $79,0 \mathrm{a}$ & $2,158 \mathrm{~b}$ \\
$(1: 4: 1)$ & $80,0 \mathrm{a}$ & $2,180 \mathrm{~b}$ \\
\hline CV $(\%)$ & 9,49 & 10,37 \\
\hline Teste F & $1,7884^{\text {NS }}$ & $5,2869^{* *}$ \\
\hline
\end{tabular}

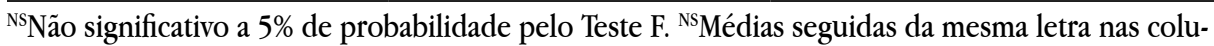
nas não diferem entre si a 5\% e probabilidade pelo Scott-Knott. "Médias seguidas da mesma letra nas colunas não diferem entre si a 1\% e probabilidade pelo Scott-Knott.

Os maiores índices de velocidade de emergência de plântulas de faveira foram observados em areia (A), casca de eucalipto triturada (C), Solo (S) + C (3:1), $S+C(1: 3), A+C(3: 1)$ e A + C (1:3) (Tabela 2). No entanto, as sementes de faveira apresentam índice de velocidade de germinação semelhantes em papel, areia, vermiculita e Plantmax® (SILVA; CESARINO, 2014).

O número de folhas, comprimento do hipocótilo e comprimento da parte aérea das plântulas de faveira foram mais expressivos em areia (A), casca de eucalipto triturada (C), Solo (S) + C (3:1), S + C (1:3), A + C (3:1), A + C (1:1), A + C $(1: 3), A+C+S(1: 2: 1)$ e A + C + S (1:4:1) (Tabela 2). De forma semelhante, as plântulas de eucalipto, bromélia cravo, buva, caruru, tamareira e faveira apresentam maiores parâmetros de crescimento com o uso de casca e/ou serragem de eucalipto, pois houve melhoria física e química na composição dos substratos (IOSSI et al., 2003; STRINGHETA et al., 2005; LIMA et al., 2008; FREITAS et al., 2010; YAMASHITA et al., 2012; SILVA; CESARINO, 2014).

Nos substratos areia (A), casca de eucalipto triturada (C), Solo (S) $+\mathrm{C}$ (3:1), S + C (1:3), A + C (3:1) e A + C (1:3), as plântulas obtiveram os maiores comprimentos totais. Enquanto os maiores comprimentos de epicótilo de plântulas de faveira foram observados em areia (A), casca de eucalipto triturada (C), Solo (S) + C (3:1), S + C (1:3), A + C (3:1), A + C (1:1), A + C (1:3) e A + C + S (1:4:1) (Tabela 3). Por sua vez, Lima e Dornelles (2002) observaram que a biomassa seca da parte aérea de plântulas de araticum (Anonna sp) foi significativamente superior em 
solo em comparação com vermiculita, areia lavada e serragem devido à composição química mais adequada.

Tabela 3. Número de folhas (NF), comprimento do epicótilo (CE), hipocótilo (CH), raiz (CR), altura (CPA) e total e razão de parte aérea/raiz de plântulas de faveira (Clitoria fairchildiana R.A. Howard. - Fabaceae) em substratos compostos por diferentes proporções de solo, areia e casca de eucalipto

\begin{tabular}{cccccccc}
\hline Substratos & $\begin{array}{c}\text { NF } \\
\text { (Unidade) }\end{array}$ & $\begin{array}{c}\mathrm{CE} \\
(\mathrm{cm})\end{array}$ & $\begin{array}{c}\mathrm{CH} \\
(\mathrm{cm})\end{array}$ & $\begin{array}{c}\mathrm{CR} \\
(\mathrm{cm})\end{array}$ & $\begin{array}{c}\text { CPA } \\
(\mathrm{cm})\end{array}$ & $\begin{array}{c}\text { CT } \\
(\mathrm{cm})\end{array}$ & $\begin{array}{c}\text { CPA/CR } \\
(\mathrm{cm} / \mathrm{cm})\end{array}$ \\
\hline Areia (A) & $1,89 \mathrm{a}$ & $13,6 \mathrm{a}$ & $5,88 \mathrm{a}$ & $8,2 \mathrm{c}$ & $19,5 \mathrm{a}$ & $27,8 \mathrm{a}$ & $2,49 \mathrm{a}$ \\
Solo (S) & $0,83 \mathrm{~b}$ & $6,4 \mathrm{~b}$ & $3,70 \mathrm{c}$ & $8,5 \mathrm{c}$ & $10,0 \mathrm{~b}$ & $18,6 \mathrm{c}$ & $1,31 \mathrm{c}$ \\
Casca de Eucalipto (C) & $2,03 \mathrm{a}$ & $12,4 \mathrm{a}$ & $6,75 \mathrm{a}$ & $13,1 \mathrm{a}$ & $19,1 \mathrm{a}$ & $32,3 \mathrm{a}$ & $1,56 \mathrm{c}$ \\
S + C (1:1) & $0,92 \mathrm{~b}$ & $7,2 \mathrm{~b}$ & $5,23 \mathrm{~b}$ & $9,5 \mathrm{c}$ & $12,6 \mathrm{~b}$ & $22,1 \mathrm{~b}$ & $1,54 \mathrm{c}$ \\
$(3: 1)$ & $2,24 \mathrm{a}$ & $12,4 \mathrm{a}$ & $6,08 \mathrm{a}$ & $10,6 \mathrm{~b}$ & $18,5 \mathrm{a}$ & $29,2 \mathrm{a}$ & $1,83 \mathrm{~b}$ \\
$(1: 3)$ & $2,25 \mathrm{a}$ & $11,0 \mathrm{a}$ & $6,30 \mathrm{a}$ & $8,8 \mathrm{c}$ & $17,3 \mathrm{a}$ & $26,2 \mathrm{a}$ & $2,10 \mathrm{~b}$ \\
A + C (1:1) & $1,97 \mathrm{a}$ & $12,2 \mathrm{a}$ & $6,38 \mathrm{a}$ & $6,5 \mathrm{~d}$ & $18,6 \mathrm{a}$ & $25,2 \mathrm{~b}$ & $3,24 \mathrm{a}$ \\
$(1: 3)$ & $1,88 \mathrm{a}$ & $15,4 \mathrm{a}$ & $6,90 \mathrm{a}$ & $7,8 \mathrm{c}$ & $22,3 \mathrm{a}$ & $28,0 \mathrm{a}$ & $3,01 \mathrm{a}$ \\
$(3: 1)$ & $2,00 \mathrm{a}$ & $13,3 \mathrm{a}$ & $6,98 \mathrm{a}$ & $7,7 \mathrm{c}$ & $20,3 \mathrm{a}$ & $30,2 \mathrm{a}$ & $3,00 \mathrm{a}$ \\
$\mathrm{A}+$ C + S (1:1:1) & $0,76 \mathrm{~b}$ & $8,4 \mathrm{~b}$ & $4,88 \mathrm{~b}$ & $6,4 \mathrm{~d}$ & $13,2 \mathrm{~b}$ & $19,7 \mathrm{c}$ & $2,14 \mathrm{~b}$ \\
$(1: 2: 1)$ & $1,56 \mathrm{a}$ & $10,2 \mathrm{~b}$ & $5,63 \mathrm{a}$ & $7,5 \mathrm{c}$ & $15,8 \mathrm{a}$ & $23,4 \mathrm{~b}$ & $2,20 \mathrm{~b}$ \\
$(1: 4: 1)$ & $1,47 \mathrm{a}$ & $12,1 \mathrm{a}$ & $6,33 \mathrm{a}$ & $6,5 \mathrm{~d}$ & $18,3 \mathrm{a}$ & $24,9 \mathrm{~b}$ & $2,82^{\mathrm{a}}$ \\
\hline CV (\%) & 23,14 & 18,54 & 11,19 & 13,78 & 14,59 & 11,26 & 18,31 \\
\hline Teste F & $8,03^{* *}$ & $6,80^{* * *}$ & $8,07^{* *}$ & $10,97^{* *}$ & $8,15^{* *}$ & $8,38^{* *}$ & $9,58^{* *}$ \\
\hline
\end{tabular}

${ }^{\mathrm{N}}$ Não significativo a $5 \%$ de probabilidade pelo Teste F. ${ }^{\text {Ns } M e ́ d i a s ~ s e g u i d a s ~ d a ~ m e s m a ~ l e t r a ~ n a s ~ c o l u-~}$ nas não diferem entre si a $5 \%$ e probabilidade pelo Scott-Knott. " Médias seguidas da mesma letra nas colunas não diferem entre si a 1\% e probabilidade pelo Scott-Knott.

Os maiores comprimentos da raiz foram observados em plântulas de faveira oriundas da semeadura em casca de eucalipto triturada (Tabela 3). De acordo com os resultados de Silva et al. (2011), o solo e esterco foram mais adequados para 0 enraizamento e o desenvolvimento de estacas de faveira devido a melhor aeração e retenção de água. As menores razões de comprimento de parte aérea/comprimento 
de raiz foram observadas em plântulas emergidas em solo (S), casca de eucalipto triturada $(C)$ e em $S+C(1: 1)$. Entretanto, somente as plântulas emergidas em casca de eucalipto trituradas apresentaram concomitantemente os maiores números de folhas, comprimento de epicótilo, hipocótilo, raiz, parte aérea e total (Tabela 3). De acordo com Silva e Carvalho (2008), as mudas de faveira com menores razões de parte aérea/raiz são mais equilibradas e vigorosas.

As plântulas mais vigorosas de eucalipto, bromélia cravo, buva, caruru, tamareira e faveira, assim como faveira (Tabela 3) estão associadas à melhoria da qualidade física e química na composição dos substratos com a adição de casca e/ ou serragem de eucalipto (IOSSI et al., 2003; STRINGHETA et al., 2005; LIMA et al., 2008; FREITAS et al., 2010; YAMASHITA et al., 2012; SILVA; CESARINO, 2014). De acordo com Gonçalves et al. (2000), a casca de eucalipto na composição de 70 a 80\% é um componente orgânico adequado para a produção de mudas.

\section{CONCLUSÃO}

A emergência das plântulas de faveira é menos influenciada pelas proporções de eucalipto no substrato (solo e/ou areia) em comparação com o vigor de suas plântulas.

Os substratos mais adequados para a emergência de plântulas de faveira são areia (A), casca de eucalipto triturada (C), Solo (S) + C (3:1), S + C (1:3), A + C $(3: 1)$ e A + C (1:3).

\section{AGRADECIMENTOS}

À Universidade do Estado do Amapá e à Amapá Celulose S/A pela cessão da estrutura, insumos e equipamentos.

Ao CNPq e à FAPEAP pela concessão de bolsa de iniciação científica aos três primeiros autores. 


\section{REFERÊNCIAS}

ANNEGOWDA, H. V. et al. The free radical scavenging and antioxidant activities of pod and seed extract of Clitoria fairchildiana (Howard) - an underutilized legume. Journal of Food Science and Technology. v. 50, I. 3, p. 535-541, 2013. Disponível em: http://ink.springer.com/article/10.1007/s13197-011-0370-8 Acesso em: 27 nov. 2015.

BENINCASA, M. M. P. Análise de crescimento de plantas: noções básicas. Jaboticabal: FUNEP, 2003. 41p.

BLUM, C. T. et al. Espécies exóticas invasoras na arborização de vias públicas de Maringá-PR. Revista da Sociedade Brasileira de Arborização Urbana. Piracicaba, v. 3, n. 2, p. 78-97, 2008. Disponível em: http://www.revsbau.esalq.usp.br/artigos cientificos/artigo40.pdf Acesso em: 27 nov. 2015.

BRASIL. Ministério da Agricultura, Pecuária e Abastecimento. Regras para análises de sementes. Secretaria de Defesa Agropecuária. Brasília: MAPA/ACS, 2009. 395p. Disponível em: http://www.agricultura.gov.br/arq_editor/file/2946_regras_ analise__sementes.pdf Acesso em: 27 nov. 2015.

CARVALHO, N. M.; NAKAGAWA, J. Sementes: ciência, tecnologia e produção. 5. ed. Jaboticabal: FUNEP, 2012. 588p.

FLORIANO, E. P. Germinação e dormência de sementes florestais. Caderno Didático $n^{\mathrm{o}}$ 2, Santa Rosa, 2004. 19p. Disponível em: http://www1.ufrb.edu.br/biblioteca/ documentos/category/18-sementes-e-viveiros-florestais?download = 221:germinac ao-e-dormencia-de-sementes-florestais Acesso em: $10 \mathrm{dez} .2015$.

FREITAS, T. A. S. et al. Produção de mudas de eucalipto com substratos para sistema de blocos. Revista Árvore, Viçosa, v. 34, n. 5, p. 761-770, 2010. Disponível em: http://www.scielo.br/pdf/rarv/v34n5/01.pdf Acesso em: 27 nov. 2015.

GONÇALVES, J. L. M. et al. Produção de mudas de espécies nativas: substrato, nutrição, sombreamento e fertilização. In: GONÇALVES, J. L. M.; BENEDETTI, V. (Ed.). Nutrição e fertilização florestal. Piracicaba: IPEF, p. 309-350, 2000. 
HONG, T. D. et al. Survival and vigour of ultra-dry seeds after ten years of hermetic storage. Seed Science and Technology, Zurich, v. 33, p. 449-460, 2005. Disponível em: <http://www.researchgate.net/publication/40119958_Survival_and_vigour_ of_ultra-dry_seeds_after_ten_years_of_hermetic_storage $>$. Acesso em: $10 \mathrm{dez}$. 2015

IOSSI, E. et al. Efeitos de substratos e temperaturas na germinação de sementes de Tamareira-anã (Phoenix roebelenii O'Brien). Revista Brasileira de Sementes, Brasília, v. 25, n. 2, p. 63-69, 2003. Disponível em: < http://www.scielo.br/scielo. php?script $=$ sci_arttext\&pid $=$ S0101-31222003000400009 $>$. Acesso em: 10 dez. 2015.

LEITE, J. F. M. et al. Antinociceptive and anti-inflammatory effects of a lectin-Like substance from Clitoria fairchildiana R. Howard seeds. Molecules. v. 17, n. 3, p. 3277-3290, 2012. Disponível em: < http://www.mdpi.com/1420-3049/17/3/3277>. Acesso em: 27 nov. 2015.

LIMA, A. L.; DORNELLES, A. L. C. Germinação de três espécies de Annona em diferentes substratos. In: CONGRESSO BRASILEIRO DE FRUTICULTURA, 18., 2002, Belém. Resumos... Belém: SBF/Embrapa Amazônia Oriental, 2002. 1 CD-ROM.

LIMA, R. T. et al. Germinação e desenvolvimento inicial de plântulas de rúcula diferentes substratos. Horticultura Brasileira. v. 26, p. 1394-1397, 2008. Disponível em: <http://www.abhorticultura.com.br/eventosx/trabalhos/ev_2/a1022_t2534_ comp.pdf > . Acesso em: $10 \mathrm{dez} .2015$.

LORENZI, H. Árvores brasileiras: manual de identificação e cultivo de plantas arbóreas nativas do Brasil. 5. ed. Nova Odessa: Platarum, 2008. 384p.

NASSIF, S. M. L. et al. Fatores externos (ambientais) que influenciam na germinação de sementes. Piracicaba: Informativo sementes (IPEF), 1998.

PORTELA, R. C. Q. et al. Crescimento inicial de mudas de Clitoria fairchildiana Howard e Peltophorum dubium (Sprenge) Taub em diferentes condições de sombreamento. Ciência Florestal, Santa Maria, v. 11, n. 2, p. 163-170, 2001. Disponível em: <http://cascavel.ufsm.br/revistas/ojs-2.2.2/index.php/ 
cienciaflorestal/article/view/1664/949>. Acesso em: 27 nov. 2015.

SANTOS, J. C. F. et al. Cobertura do solo no controle de plantas daninhas do café. Pesquisa Agropecuária Brasileira, v. 37, n. 6, p. 783-790, 2008. Disponível em: < http://www.infoteca.cnptia.embrapa.br/handle/doc/571932>. Acesso em: $10 \mathrm{dez}$. 2015.

SILVA, B. M. S.; CARVALHO, N. M. Efeitos do estresse hídrico sobre o desempenho germinativo da semente de faveira (Clitoria fairchildiana R.A. Howard. - Fabaceae) de diferentes tamanhos. Revista Brasileira de Sementes, Pelotas, v. 30, n. 1, p. 55-65, 2008. Disponível em: < http://www.scielo.br/pdf/rbs/v30n1/a08v30n1.pdf>. Acesso em: 27 nov. 2015.

SILVA, B. M. S.; CESARINO, F. Germinação de sementes e emergência de plântulas de faveira (Clitoria fairchildiana R.A. Howard. - FABACEAE). Biota Amazônia, Macapá, v. 4, n. 2, p. 9-14, 2014. Disponível em: < http://periodicos.unifap.br/index. php/biota/article/viewArticle/661> . Acesso em: 27 nov. 2015.

SILVA, B. M. S.; MÔRO, F. V. Aspectos morfológicos do fruto, da semente e desenvolvimento pós-seminal de faveira (Clitoria fairchildiana R. A. Howard. Fabaceae). Revista Brasileira de Sementes, Pelotas, v. 30, n. 3, p. 195-201, 2008. Disponível em: < http://www.scielo.br/pdf/rbs/v30n3/26.pdf> Acesso em: 27 nov. 2015.

SILVA, R. R. et al. Efeito de substratos no estabelecimento de mudas e produção de biomassa de Clitoria fairchildiana R. Howard e Gliricidia sepium. Cadernos de Agroecologia, v. 6, n. 2, p. 1-5, 2011. Disponível em: < http://www.aba-agroecologia. org.br/revistas/index.php/cad/article/view/12114/8347> . Acesso em: 27 nov. 2015.

SOUZA, L. A. G. et al. Desenvolvimento e nodulação natural de leguminosas arbóreas em solos de Pernambuco. Pesquisa Agropecuária Brasileira. Brasília, v. 42, n. 2, p. 207-217. 2007. Disponível em: < http://www.scielo.br/pdf/pab/v42n2/09.pdf>. Acesso em: 27 nov. 2015.

STRINGHETA, A. C. O. et al. Germinação de sementes e sobrevivência das plântulas de Tillandsia geminiflora Brongn, em diferentes substratos. Acta Scientiarum. 
Agronomy, Maringá, v. 27, n. 1, p. 165-170, 2005. Disponível em: <http:// periodicos.uem.br/ojs/index.php/ActaSciAgron/article/viewFile/2138/1246>. Acesso em: 10 dez. 2015.

YAMASHITA, O. M. et al. Emergência de Conyzas influenciada pela presença de resíduos vegetais. Revista Agrarian, Dourados, v. 5, n. 18, p. 310-318, 2012. Disponível em: <http://www.periodicos.ufgd.edu.br/index.php/agrarian/article/ viewArticle/1425>. Acesso em: 10 dez. 2015.

ZAR, J. H. Biostatistical analysis. $4^{\text {th }}$ ed. New Jersey: Prentice-Hall, 1999. 121p.

Recebido em: 14 de janeiro de 2016 Aceito em: 18 de julbo de 2016 